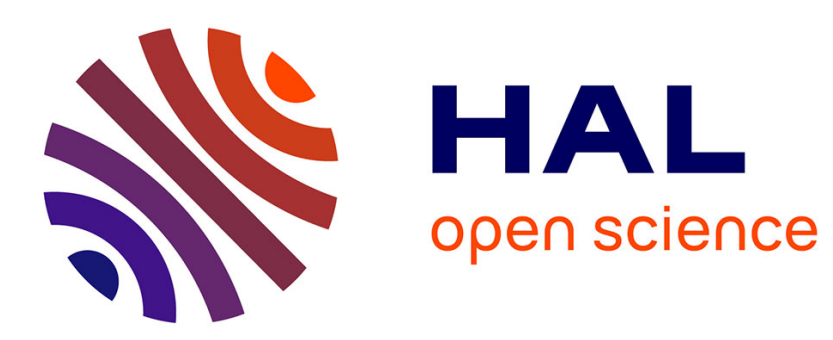

\title{
Symbolic Power for Beginners: The Very First Social Efforts to Control Others' Actions and Perceptions
}

Wilfried Lignier

\section{To cite this version:}

Wilfried Lignier. Symbolic Power for Beginners: The Very First Social Efforts to Control Others' Actions and Perceptions. Sociological Theory, 2021, 39 (4), pp.201-224. 10.1177/07352751211050660 . hal-03499687

\section{HAL Id: hal-03499687 https://hal.science/hal-03499687}

Submitted on 21 Dec 2021

HAL is a multi-disciplinary open access archive for the deposit and dissemination of scientific research documents, whether they are published or not. The documents may come from teaching and research institutions in France or abroad, or from public or private research centers.
L'archive ouverte pluridisciplinaire HAL, est destinée au dépôt et à la diffusion de documents scientifiques de niveau recherche, publiés ou non, émanant des établissements d'enseignement et de recherche français ou étrangers, des laboratoires publics ou privés. 


\title{
Symbolic Power for Beginners: The Very First Social Efforts to Control Others' Actions and Perceptions
}

\author{
Wilfried Lignier \\ National Center for Scientific Research (Paris, France)
}

Keywords:

Early Socialization, Symbolic Power, Children, Ethnography, Social Agency

\section{Corresponding Author:}

Wilfried Lignier

Centre européen de sociologie et de science politique

Ecole des hautes études en sciences sociales

Bureau A5-34

54 bd Raspail

75006 Paris

France

+33617539337

wilfried.lignier@cnrs.fr 


\title{
Symbolic Power for Beginners: The Very First Social Efforts to
}

\section{Control Others' Actions and Perceptions}

\begin{abstract}
Becoming a social agent requires the ability to gain some power over others' actions and perceptions. For that purpose, symbolic practices and language matter, especially when physical means of control are unavailable, ineffective, or illegitimate. Based on an in-depth ethnographic study, I analyze such a process of symbolic empowerment from the viewpoint of very young practitioners: children age 2 to 3 years. I explore the symbolic means through which toddlers seek control over adults, from simple signals, naming, and politeness, to basic fictionalization. Children's social backgrounds, not just age and development, inform their tendency to affect adults through words. The content of symbolic practices is determined by preexisting social hierarchies, between persons, groups, and institutions. In fact, the crucial challenge for young children is to take advantage of these hierarchies, by publicly putting them in line with their own emerging interests.
\end{abstract}

We are not born social agents. Human sociality is admittedly immediate insofar as we accept that sociality simply means one's existence is relationally informed by the actions of other past and present humans. But human agency is clearly not given at birth. Agency, as one definition puts it, requires an "engagement by actors of different structural environments ... which, through the interplay of habit, imagination, and judgment, both reproduces and transforms those structures" (Emirbayer and Mische 1998:970). Very young children are "engaged" in the social world they discover. Studies in developmental psychology demonstrate that even newborns perform intensive observation and exploration of their environment by actively tracking objects, following gazes, or trying to imitate gestures (Farroni et al. 2004; Johnson et al. 2008; Vincini et al. 2017). But the effects of such precocious activity on concrete situations remain limited. Newborns are not in a position to "reproduce and transform" the social context in which they live, even at the immediate interactional level, as they do not control others' actions or perceptions toward them. Children only become social agents as they acquire the ability to 
produce some practical consequences of their own orientations, namely those that are not spontaneously carried out or assumed by others (or not sufficiently to affect the context). In other (Weberian) words, the emergence of human agency requires the exercise of an elementary sort of power: the power to bring about what would not take place without a challenge of some sort to the ongoing social activity of others (Dahl 1957; Lukes 2005; Reed 2013; Weber [1922] 2019).

What exactly is this first power from a sociological viewpoint? How does it work? What knowledge and skills does it require? Does it correspond to early social differences and hierarchies between children? Ultimately, how does exploring the earliest human efforts to gain agency invite us to think anew about power itself? In this article, I address these questions through an in-depth ethnographic study conducted in a French daycare center with children age 2 to 3 years. I assume the central theoretical hypothesis that even if physical and material means of constraint are observable in the early years of life (as documented by the psychology of aggression, see Alink et al. 2006; Hay et al. 2011), the power at stake for very young children is crucially a symbolic power. Without necessarily being "individuals consciously acting to affect others" (Lukes 2005:41-42), toddlers have an objective interest in using their first words, sentences, or emergent narrative skills to affect adult ways of acting and thinking.

The notion of symbolic power plays a pivotal role in Bourdieu's sociological theory (Bourdieu 1993, 1994; Schwartz 2013; Wacquant and Akçaoğlu 2017). Generally speaking, symbolic power can be defined as a social constraint imposed on practice through the circulation of symbols, that is, of perceived forms collectively constituted as significant. Bourdieu (1993) first used the concept to criticize the notion of "communication." The idea is to emphasize two important aspects of symbolic production in social life. First, symbols are almost always used in relation to social struggles (of various scales), and seldom as pure means of cooperative information or knowledge. Second, social agents engaged in symbolic relationships often have 
unequal means to produce and receive efficient symbols, given their social resources, habits, and status. Bourdieu mostly explored the structural, historical, and macrosociological dimensions of symbolic power (e.g., Bourdieu 2014). He underscored the role of symbolic systems in the longterm maintenance of social orders, highlighting the role of the state and its affiliated institutions such as the school. In this perspective, symbolic power mostly consists of a structural imposition, by dominant social classes, of very general social classifications and "principles of division" (Bourdieu 1993), which come to represent inescapable and unquestionable means of (self-) perceptions for all, including members of dominated social classes.

However, another heuristic possibility offered by the concept is to adopt a practical, localized, and microsociological view of symbolic power. Ordinary symbolic practices observed in face-to-face interactions between persons (including children) can be seen as instruments of social struggles. Reed (2013:207), who underscores the importance of what he calls the "performative/pragmatist dimension of power," describes such a theoretical move:

The question becomes, To what degree do the timing, emotional resonance, and rhetorical effectiveness of actions - in contrast to the social position of the actors doing the actions, or the codes and narratives cited by actors who "frame" an issuegive some actors control over others, or give some actors increased capacity to move in the world?

This shift in scale results in new theoretical and empirical challenges. The social struggles at stake may be far more specific and less spectacular than the struggles between dominant and dominated social classes. The effect of symbols on the balance of power may be based on tiny prosodic, semantic, or syntactic details. Sociological attention shifts from generic categorizations, or institutionalized narratives, to specific utterances, forms of address, and improvised stories. That said, the connection with the "classical" perspective on symbolic power is carefully maintained. Even when approached through localized, ordinary practices, symbolic power remains dependent on-or more precisely built on-sociohistorical structures. Acquired 
dispositions, social positions, and social interests condition the resources, abilities, and strategies of practitioners (even very young ones), yet the symbols used cannot be invented locally, otherwise they would lose their meaning in both the linguistic and social sense of the term. Symbols necessarily derive from macrosociological processes, through which certain meaningful and appropriate forms of expression become available and practicable. These typically include linguistic schemes (corresponding to "principles of division"), as well as canonical phrases, idiomatic formulas, habitual narratives, and recurring words that surrounding institutions sustain and promote.

I posit that young children fall within this general situation in their quest for greater social agency. The symbolic power they exert on others, especially through language practice, depends on their social characteristics, as far as they correspond to already constituted dispositions (what has been learned, embodied), resources (notably cultural ones), and interests (if some personal fixation and consistence in orientation already exists). In addition, the types of symbols children display are determined by social processes that largely exceed children's individual scope. What children say is rarely a pure, original creation. Most of the time, it has been said before (by caregivers, peers), and often included in some sort of collective legitimation (e.g., an educative norm) justifying symbolic transmission and learning.

The core of the article consists of the analysis of two primary types of social power that symbolic activity opens or facilitates. The first is the power to affect others' actions so they match individual, non-shared goals; simply put, the power to make people do, within a given interactional context, what they otherwise would not spontaneously do. The second type of power is the power to foster certain perceptions in others, particularly for the valorization of personal properties, and ultimately for self-valorization. As we will see, for young children, valorized 
personal properties are inseparably concrete personal possessions and abstract personal characteristics.

Examination of the ethnographic data confirms - counter to the common notion that words are mostly dedicated to communication and information - the importance of power-related issues in early symbolic practices. I find that because they require selective social resources, and in turn lead to different practical opportunities, these practices are both a consequence and a cause of early social inequalities. But most importantly, the analysis demonstrates that in the course of concrete face-to-face interactions, the exercise of symbolic power crucially relies on individuals' ability to evoke, via chosen symbols, diverse forms of social authority included in language as a sociohistorical product. Young children do not try to invent original ways of imposing themselves on others. Rather, their efforts consist of reactivating, for their own benefit, the experienced social effectiveness of certain strategic words, such as proper names, polite forms of address, or fictional narratives.

\section{BACKGROUND AND JUSTIFICATION}

\section{Reintegrating Issues of Power in the Sociology of Childhood}

The social study of children, previously a (marginal) aspect of the sociology of education or the family, has emerged in recent decades as a dedicated sociological subfield (Corsaro 1985, 1997; James and Prout 1990; Pugh 2009, 2014; Qvortrup, Corsaro, and Honig 2009). The most distinctive feature of this tradition is its insistence on children's agency. This theoretical starting point implies that children are not reduced to objects of social action, as in the classical functionalist analysis of socialization, but are instead considered social subjects whose specific viewpoints and activities deserve sociological attention. Hence the frequent use of ethnographic approaches to children's daily interactions and practices, typically in social settings where 
children enjoy a certain autonomy vis-à-vis adult control, such as school yards, playgrounds, or bedrooms.

This perspective has enriched our vision of childhood, notably by offering detailed accounts of children's peer culture, that is, the symbolic forms and actions that are of particular importance to children. But here culture is rarely connected to power-related issues. Childhood scholars typically consider children's symbolic production, often equated with children's folklore, in relative isolation, as if it were not connected to adult institutions, adult cultural production, and adult interventions in the course of interaction. Overlooking this relation to adults, not only in terms of general framing, but also in practice-making, prevents analysts from interpreting children's symbolic activity as a possible incarnation of basic social struggles. In contrast, recent work rooted in a traditional sociology of education (Bourdieu and Passeron 1977) — but paying more attention to the role of children themselves in the process of social transmission - explores the decisive contribution of children's face-to-face interactions in class reproduction (Calarco 2011, 2014; Lareau 2003; Streib 2011). These authors demonstrate how middle-class children develop, through family training, a distinctive tendency to speak out in institutional settings (e.g., school), which helps them secure social advantages. These findings echo mine, although I deal with younger children outside the classroom.

Another shortcoming of this literature concerns the sociological approach of agency. Within the sociology of childhood, children's agency essentially stands for an unquestioned axiom, rather than an object of inquiry. The social process through which children gain agency is almost never explored, despite questions surrounding the social conditions of children's agency and its strong variations across historical and cultural contexts (Lancy 2012). This theoretical situation is surprising, because the sociology of childhood was partly inspired by ethnomethodology (see, e.g., Corsaro 1985), which, after Sack's (1992) seminal work, has 
focused on children's observable strategies to make their way into adult conversations (Filipi 2009; Gardner and Forester 2010; Keel 2016).

Even when the context opens practical opportunities for children to act as relatively autonomous, powerful social agents, how do they effectively seize this opportunity? How do they learn to express and fulfill their personal interests? What does this require on the part of children and their immediate environment? I hypothesize that the ability to acquire and use symbolic resources is crucial in this regard. We can also anticipate that children's agency not only results in, but stems from, power relations.

\section{What Can We Do (To Others) with Basic Cultural Elements?}

Because symbols are the basic constituents of culture, a sociological study of early symbolic empowerment can also draw on cultural sociology. This is all the more true when cultural sociology includes an interest not just in cultural systems, but also in the relations between culture and individual practices or perceptions. Expanding on the idea that abstract, general culture may have less importance in day-to-day social life than "culture in action" (Swidler 1986) and "culture in mind" (Cerulo 2002; DiMaggio 1997), current cultural sociology does precisely that (Ignatow 2009; Lizardo 2006, 2016a; Vaisey 2009; Vaisey and Lizardo 2010; Vaisey and Valentino 2018). Despite its relative diversity, this research sets out from a common question: what do people do with culture?

Interestingly for my purposes, the answer often concerns power-related issues. Culture is typically seen as an efficient tool for the affirmation of social class. Previous "distinction studies" (after Bourdieu 1984) have explored the relationship between class and culture, but mostly as a structural, static phenomenon. The originality of recent research is to focus on distinction in action, namely, the relationship between day-to-day cultural performances and the production and 
reproduction of social hierarchies. Studies demonstrate, for instance, that the concrete establishment of socially selective friendships requires the interactional use of distinctive symbolic forms, such as a certain type of music (Lizardo 2006), cultivated conversation (Lizardo 2016a), or TV programs (Friemel 2011). If cultural performance represents such a crucial contribution to the everyday shaping of distinction, it is partly due to a widely shared ability to give social meaning to cultural practices when they are experienced in interaction. Even implicit, ambiguous, weakly structured cultural goods, such as perfume, prove to be easily decipherable markers of social position (Cerulo 2018). In summary, both the efficient display and reception of symbols should be taken into account in understanding the making of social hierarchies.

Within cultural sociology, most of the symbolic forms at stake are quite complex, given that a musical piece, conversation, or TV show consists of elaborate associations of harmonies and melodies, topics and rhetorical sequences, and images and stories. Can we imagine that more elementary symbolic forms — symbols in the narrow sense of the term—similarly intervene in social action, and more specifically are involved in power relations? The question is worth asking when dealing with symbolic beginners such as young children, who are definitely not able to affect others, or to be affected themselves, by the use of complex cultural forms.

Such a shift from complex to elementary symbolic forms is sometimes assumed in the literature, but this work then shifts theoretical priorities - the social logic of imposition, distinction, selection, and segregation is set aside, and questions of knowledge and emotional construction are favored (see, e.g., Lizardo 2016b, which discusses the role of "cultural symbols" in the formation of meaning). In contrast, I posit here that most basic cultural elements - the first words learned by toddlers - are associated in practice not just with cognitive self-construction, but also with power in the usual sense of the term (i.e., observable efforts to control people's actions and perceptions). To a certain extent, this perspective echoes Cerulo's (2018) ambition to 
connect the microsociology of tiny cultural operations (e.g., deciphering perfumes) to powerrelated issues (making cultural boundaries). Note, however, that I approach the exercise of power in a more incarnate fashion: I explore the role of symbols in children's efforts to control persons directly, in the interaction itself. Here, culture does not just sustain and reproduce a generic, external social order. Rather, culture functions as an instrument for power practices, whose effectiveness is constantly experienced by children, particularly in the course of their successful and unsuccessful interactions with adults.

\section{Early Language Practices as Seen by Psycholinguists}

Because the study of early symbolic practices concerns very young children, we can draw on developmental psychology, and in particular, developmental psycholinguistics. This field gathers linguists and psychologists around the same question: how do humans acquire language skills? The corresponding research is wide-ranging, and my objective is certainly not to summarize it in a few lines (for an overview, see Saxton 2017). I will instead refer to a specific research perspective that in several ways echoes the sociological approach, namely the "usagebased" perspective on language development.

Usage-based research is associated with the work of Tomasello $(2003,2009)$, but its origin can be traced back to much earlier psychological contributions (Bruner 1983; Vygotsky [1934] 1986). Tomasello broke with the long-standing dominant Chomskian idea that language development is not due to verbal stimuli in a child's environment, but consists of the progressive maturation of innate, internal grammatical skills. Instead, the usage-based theory of language development gives a central role to language practices as they occur in context, first on the part of children's parents, siblings, or caregivers, and then on the part of the children themselves. The theory is based on two major hypotheses that can be tested by empirical studies. First, language 
stimuli in the early years are not "poor," as Chomsky proposes, but are rich quantitatively (children are exposed to an enormous amount of speech) and qualitatively (children experience diverse linguistic forms, from simplified child-directed speech to complex overheard adult conversations). Second, children are not passive in their relationship to ambient language: the very reason language can be learned is that, from the start, humans actively try to make sense of their surrounding symbolic life by putting it in the service of their own actions.

Some phrases Tomasello (2003:3, 13, emphasis added) used in his description of early symbolic activity suggest it has something to do with children's social empowerment:

Linguistic communication involves in all cases the attempt of one person to manipulate the attentional or mental states of other persons.... When a child learns the conventional use of linguistic symbols, what she is learning are the ways her forebears in the culture found it useful to share and manipulate the attention of others in the past.

However, as implicitly signaled by use of the phrase "linguistic communication" for the generic designation of language practices, for Tomasello and his followers, the "manipulating," conflictual dimension of early symbolic performances is neglected in favor of its "sharing," cooperative dimension. In other words, current developmental psychologists rarely consider that language learning could be crucially fueled by children's basic need to impose their own interests on others, or to secure their emerging social position and situation.

Taking power into account may help overcome certain difficulties faced by usage-based theorists. A large array of empirical research is dedicated to establishing correlations between the frequency of a given linguistic (grammatical, semantical) element in parental speech and its (delayed) frequency in children's speech (Diessel and Hilpert 2016; Griev and Divjak 2012; Lieven 2010). The theoretical assumption is that "usage" above all means "repetition," and children will more efficiently learn an aspect of language if they have a large number of situations for imitation. This assumption is right most of the time, and numerous correlations 
have been found; the problem is that "frequency is not the key to all doors" (Tribushinina and Gillis 2017:19). Some rare words, expressions, or structures are learned quickly, and vice versa. Psycholinguists are currently exploring several explanations: the variable effect of frequency could be linked to the intrinsic perceptibility of linguistic forms, their relative structural complexity, the degree of conceptual abstraction, or the little-explored notion of "communicative importance" (p. 26). This phrase reflects the idea that beyond repetition, children learn what they "need to express" (p. 27), even if it is not frequently demonstrated by other social agents in their immediate environment. Such a perspective echoes mine in the sense that children's empowerment becomes a crucial criterion of selection within the symbolic environment.

Usage-based developmental psycholinguistics, even in the form of frequency studies, does produce important results for sociologists. These studies correspond to precise quantitative evaluations of the linguistic worlds of young children assessed in the natural setting of everyday life (for a review, see d'Apice, Lathan, and von Stumm 2019:1414-17). Most interestingly, some of this literature explores social differences. For example, using the Language Environment Analysis (LENA) protocol—which enabled automated processing of all vocalizations during a consecutive 12-hour period for 329 English-speaking 2-year-olds - a recent study demonstrated that social class (assessed through maternal level of education), the number of adults words (either directed to the child or overheard), and child speech-related vocalizations are strongly correlated (Gilkerson et al. 2017). Toddlers from lower-SES families (mothers with only some high school education) are exposed to a mean of 11,358 adult words and produce a mean of 1,466 vocalizations, whereas toddlers from higher-SES families (mothers with a college degree) are exposed to a mean of 14,848 adult words ( +31 percent) and produce 2,085 vocalizations $(+42$ percent). The study found no significant gender differences, but we cannot exclude this possibility appearing in larger samples or with a focus on specific social groups. ${ }^{\mathrm{i}}$ In any case, 
these findings offer a reminder that symbolic resources are not equally distributed, even in the first years of life, and are therefore not equally available for social empowerment. My ethnographic observations confirm this reality, and I explore the interactional consequences.

\section{DATA AND METHODS}

\section{Toddlers in a Daycare Center}

My ethnographic study focuses on children age 2 to 3 years. Before age 2, children's symbolic capacities appear too limited for the assessment of personal acts of power. While they can generally walk, deliberately moving toward objects and persons without the help of an adult, their language remains poor: according to psycholinguists, "multi-word utterances with basic grammatical features" only appear at 24 months (Saxton 2017:17). Yet before age 3, symbolic activity remains rudimentary, notably in the absence of schooling. ${ }^{\text {ii }}$ This means we can observe fairly elementary symbolic action, which may facilitate the analysis.

I conducted fieldwork from late 2015 to mid-2016 in a public daycare center located in Paris, France. This is by no means a "representative" social location, if that notion has any value with respect to ethnographic approaches. In France, in 2013, only 13 percent of children under age 3 attended a daycare center, with great variations, notably between urban and rural areas. In the Greater Paris area, the proportion was 24 percent. The daycare center I selected was located in northeast Paris, in a neighborhood with a mix of social classes. My intention was to have substantive class variations among children, but in reality a majority of children were from a middle- to upper-middle-class background, with only a minority coming from very disadvantaged social backgrounds.

I observed 28 children, 11 boys and 17 girls. These 28 children were all enrolled in the same section of the daycare center, reserved for children born in 2013. Some children were born at the beginning of the year and some at the end, so almost one year separated the younger ones 
from the older ones. The section included 14 children from an upper-middle-class background (e.g., their parents worked as business executives, engineers, artists), six from a middle-class background (e.g., their parents worked as clerks or were self-employed), and eight from a working-class or poor background (e.g., their parents worked as waiters, housekeepers, or were unemployed). Half the children (14) had at least one parent born in Africa or Asia. Social class and immigrant background were obviously intertwined in this field: only two of the 14 uppermiddle-class children were from Asian or African backgrounds, compared to six of the eight working-class children. I therefore do not analyze class effect and immigration effect separately. Nevertheless, among my respondents, being from an immigrant family generally meant the child did not speak French at home, a crucial aspect of social background with regard to the exercise of symbolic power in a francophone context (the daycare center). When this linguistic characteristic is of particular importance for the interpretation, I mention it in the text.

\section{Nature of the Observations}

I went to the daycare center most mornings for a number of weeks, first between November 2015 and January 2016 (primary period of observation), and then between May and June 2016 (additional period of observation). I observed each child (interacting with local peers) for a mean duration of three hours during the primary period (one girl, Cléa, was mistakenly observed twice). During the additional period, eight children of particular interest—chosen for contrasts in age, gender, and social background - were observed for two more hours. I ultimately completed approximately 102 hours of direct observation ( 86 hours during the primary period; 16 hours during the additional period).

My approach was participant observation, in so far as my own action in the field was included in the observation and analyzed as a possible determinant of the children's activity (Fine 
and Sandstrom 1988; Højholt and Kousholt 2014). However, with very young children, participation does not entail integration within a peer group, because such a peer group does not exist; the boundary between adults and children is objectively and subjectively far too strong to be crossed by the researcher, even in a superficial manner. As a result, although I avoided any position of authority in the daycare center (except in emergencies), the children largely acted in the same way with me as they did with the childcare assistants.

In addition to ethnographic observation, I collected different empirical elements, notably through interviews with assistants $(n=5)$ and parents $(n=22)$. That said, I almost exclusively built on my ethnographic observations for this article.

\section{POWER OVER OTHERS' ACTION: HOW TO AFFECT ADULT ROUTINES WITH WORDS}

\section{The Uncertainty of Simple Signals}

When adults strongly control the interactional context, children's social empowerment crucially depends on their ability to act upon adults, and make them do what they would not spontaneously do otherwise. ${ }^{\text {iii }}$ If physical violence were allowed, it would obviously be inefficient for that purpose (adults being physically stronger). Thus symbolic means are required. This does not necessarily imply language practices, as children can rely on non-verbal symbols, such as signals: they can cry or make other sounds, use gestures such as pointing or waving hands, or simply stare at caregivers in an insistent manner, so they eventually realize they are supposed to do something (different). Here are a few examples of such signaling practices:

[While the children are playing on the rooftop,] Ibtissam [girl, 2:10, mother unemployed, from Ivory Coast] is trying to climb on top of a mushroom-shaped concrete block. She fails repeatedly, and cries with anger. The assistant ultimately helps her climb on the mushroom. (Dec. 2015) ${ }^{\mathrm{iv}}$

The assistant decides to move Jim to where Aaron was previously sitting, in front of a plastic board game. Aaron [boy, 3:01, mother unemployed, from Cameroon] whines 
and wants his place back. The assistant tells him: "I know Aaron, but right now there isn't enough room for anyone." (May 2016)

As I sit in a foam chair, I hear a child grunting with effort. I realize that Giulia [girl, 2:03, mother researcher], who is next to me, is apparently having a hard time taking off one of her shoes. She is actually moving the shoe near her foot, and has already managed to take it off (it's quite easy to do as the shoe has Velcro straps). She doesn't really need help. The shoe ultimately drops out. Strangely, Giulia puts it back on her foot, and keeps on grunting. She eventually places her leg on my lap so that I solve the "problem." (Nov. 2015)

The last example shows that such practices, albeit basic, already deal with more than purely "technical" issues, that is, getting someone to do what you cannot do by yourself. There is something more to being helped, to orienting adult actions toward personal interests. The action itself gives social credit to these interests, and confirms that what the child is seeking to do deserves to be supported rather than condemned or ignored. We shall return to this question of valorization when dealing with power over others' perceptions.

For now, it is important to underscore that these most basic symbolic practices are generally performed by the youngest children (e.g., Giulia), but also by older children from working-class or poor social backgrounds or from immigrant families (e.g., Ibtissam and Aaron). These children all have relatively low verbalization skills (in French). Such children engage in symbolic activity and use it to gain social agency (in this case through the solicitation of adults), but it is essentially limited to signals rather than signs. Signals can draw attention within the interactional context: adults turn their heads when they hear a child crying, or look more carefully when they see arms moving about, in an effort to see what is happening. In other words, signals can be fairly efficient in indicating a specific location for a requested action. But beyond that, signals remain relatively weak social tools for at least two reasons. They do not convey clear information about who exactly should act, and they do not define why a non-spontaneous action by others is necessary, appropriate, or interesting for the targeted social agent. In other words, signals rely on the routinized management of situations (e.g., a crying child must generally be 
consoled), without the possibility of customizing a situation through expression of special emotions or reasons.

In the Name of Familiarity

Children with greater verbal skills - namely, older children or children from the most favored social backgrounds — can improve their power over adult actions by moving beyond simple signaling. Several degrees of symbolic refinement can be distinguished in this direction, with the first degree being the simple act of calling an adult by name. This practice is not so easy to perform, as using a name implies attention to naming practices in surrounding interactions, or a previous question to the adult (the latter corresponding to special verbal skills). It also requires memorization. Ultimately, calling someone by name means assuming a minimal "sense of entitlement" (Lareau 2003), as it corresponds to a direct solicitation: children must not be afraid of bothering this adult, and must also consider their solicitation to be worthwhile. In short, in addition to knowledge of the adult's name, children must overcome various social reasons for hesitating to use it in an effective interaction.

As a newcomer in the interactional context, whose name had to be learned and mastered by children, I personally experienced social differences in children's naming abilities. Even though I was "officially" presented to everyone at the beginning of the fieldwork, and was regularly called "Wilfried" by childcare assistants in front of the children, for a long time, a large majority of children seemed to not know my name, or at least did not use it even when they obviously wanted to call me. The youngest children either used gestures and non-verbal calls, or sometimes said, "Hey, the daddy!" as a generic solicitation. Older children with relatively few verbal resources, given their social background, also used generic terms, as in the following sequence: 
Aaron [boy, 2:05, mother unemployed, from Cameroon] has a problem with two building blocks: they are stuck together, and he cannot separate them. He calls me:

“Mister! Do you want to remove?" I separate the two plastic pieces. (Nov. 2015)

In contrast, some children were quickly able to call me by name. It happened 28 times during my fieldwork; among these 28 observations, 26 came from the oldest children, born in January or February 2013, and 22 were from children with an upper-middle-class background. One of the most verbally proficient children in the section, Garance, mastered my name in the first days I was at the daycare center:

Garance [girl, 2:09, mother purchasing manager] is trying to remove a large doll from the little kitchen where she is playing, but is having a hard time. "Oh! The baby is stuck!" she says, turning her head in my direction. I deliberately do not react. She says: "Wilfried! The baby is stuck!" (Nov. 2015)

Here, Garance deliberately replaced a generic term of exclamation (“Oh!” [i.e., a signal]) with a proper name ("Wilfried!") to improve the social efficiency of her call. By doing so, she targeted a specific adult (me), thereby lessening the chance the person would ignore the call. This was effective not only because the call lost its generality and ambiguity, but also because it is hard, in practice, not to react when you hear your first name. Moreover, a proper name evokes some social proximity. Complete strangers cannot be called by their first name. When Garance called me "Wilfried," she implicitly demonstrated she has some shared experience with me, that I am a pretty familiar person to her. This expressed familiarity functions as an invitation to act, so to speak, as family members do: trying to be as helpful as possible, acting in accordance with the interest of other family members. The fact that familiarity is at stake is further demonstrated by Garance's ability over time to customize my name to further convey she was familiar with me: “Wilfried!” was sometimes replaced by “My sweet Wilfried!” (“Mon petit Wilfried!') or “Willy!" ("Wilfriedou!”). 
In summary, compared to signals, naming is not just a symbolic tool for reducing uncertainty about the identity of the person the child is calling. It is already a normative sign, conveying a kind of moral obligation: not just a descriptive "you, help me" (i.e., an answer to the "Who?" question); but rather something like “you, because I know you and you know me, you have to help me" (i.e., an answer to the "Why?" question). This normative content of early symbolic practices, directed toward adult action, can be developed, on the condition that verbal resources are developmentally and socially available in children.

\section{What (Some) Children Can Do with Politeness}

The selective use of polite forms of address exemplifies this point. Linguistic scholars highlight that politeness, whatever its precise form, is not a superficial and arbitrary feature of speech acts, but is often pivotal in concrete language interactions: it functions as a central social mean for the strategic achievement of many non-shared goals (Brown and Levinson 1987; Mills 2015). This literature includes research on the differential role of politeness in early socialization, but only in terms of gender (young girls apparently use more polite forms than do boys); the results are contested, notably because of important variations depending on cultural context (Ladegaard 2004). In my own fieldwork, two aspects struck me: first, although children as a whole did not use many words given their very young age, they did use several polite forms of address; second, this early politeness was distributed according to a class-based logic. Most of the children were prompted to use direct, unmitigated forms of request in their interactions with adults; for example: “[During lunchtime,] Justine [girl, 2:00, mother consultant] says 'Want more!' raising her hand towards the fruit but without naming it" (Nov. 2015).

Direct requests were particularly prevalent given that politeness - in accordance with a general idea that daycare centers are not supposed to be schools - was explicitly not taught at the 
center. In meetings with parents, assistants reminded them that their role was absolutely not to force children to say "Please" or "Thank you," because they favored children's spontaneity and exploration. Nonetheless, emerging politeness was observable in some children, especially children from the most privileged social backgrounds. For instance, my fieldnotes mention 11 occurrences of a child using the word "Please" in an interaction, and 10 of those statements came from a child with an upper-middle-class background. These children were sometimes very young:

[During a reading session] Pablo [boy, 2:04, mother architect] seems frustrated because he wants to keep looking at a picture on the page that was just turned. He points to the previous page and quickly tells the assistant: "Please, I want to see it!" (Nov. 2015)

Pablo was only 2 years and 4 months at the time, but he was raised in a very cultured and talkative family (both parents were highly educated and employed in the cultural sector; the interview with his father lasted more than five hours). Such language practice was rarely observed in children from working-class or poor social backgrounds, even among the oldest children. For "Please," the only exception in my field notes is the following:

Aaron [boy, 3:01, mother unemployed, from Cameroon] asks for a red maraca the assistant is carrying in her hand. "To me!" he says boldly. The assistant protests: "No, you must not ask like this ... "Please," Aaron adds. The assistant gives him the maracas. (May 2016)

Aaron did not use a polite form of address spontaneously, but only because he was asked to do so by the assistant (who violated the local norm of not teaching politeness to children). Interestingly, such a sequence shows that the general non-usage of politeness among working-class or poor children, and among children from non-francophone immigrant backgrounds, is not a pure question of linguistic skill. Aaron clearly knew and uttered the word "Please," and he understood the pragmatic role of the word. This suggests language style (and interactional culture, more broadly) is involved here, rather than just language skill. In fact, previous research on workingclass language styles finds directness is valorized as an esthetical and ethical feature and is 
associated with clarity (instead of pointless complexity) and frankness (rather than hypocrisy)

(Bernstein 1971; Lareau 2003; Miller, Cho, and Bracey 2005).

Please, Sorry, and the Social Magic of Convention

Why exactly do socially privileged children find politeness useful in their interactions with adults? The question is worth asking as long as this distinctive characteristic is not considered solely the result of earlier socialization in the family (which it is), but also as a performance produced and reproduced when it makes sense in the course of practice. As with proper names, children seemed aware that words such as "please" and "sorry" include some normative content that could improve their personal power over adult actions. They anticipated the effect of a polite speech act compared to non-verbal action (extending one's hand, forcing one's way into a place) or actions associated with purely imperative and descriptive words (e.g., "give me that thing"). The following sequences clearly illustrate this implicit anticipation:

[During lunchtime] Owen [boy, 2:11, mother unemployed, from Senegal] seems to be asking for something, but the assistant does not get it (nor do I). The assistant ultimately says: "Speak, Owen, I can't understand you ... " At this very moment, Chloe [girl, 2:08, mother reflexologist] calls the assistant: "Mary, please, can you come?" The assistant comes to Chloe, ready to help her put food on the little plastic tray. But it turns out that Chloe is perfectly able to manage on her own. (Dec. 2015)

[In the bathroom] I am sitting on the last step of a small stairway, where I usually wait while the children wash their hands. Livia [girl, 2:10, mother schoolteacher] stands before me and says: "I want to go up!" As I do not let her have my place, she starts to move ahead, pushing me gently and saying: "Sorry Madam, sorry Sir!" Neyla [girl, 2:04, mother unemployed, from Guinea] arrives and also tries to go up the stairs, but without saying anything. Then Andy arrives, does the same, and repeats Livia's words: "Sorry Madam! Sorry Madam!" (Nov. 2015)

Garance [girl, 2:09, mother purchasing manager] is standing at one end of a long, rectangular table, and intends to take a book that has been left at the other end. The assistant is sitting at the table with two children, and they are reading together. Surprisingly, instead of skirting around them Garance bumps into the small group and repeatedly says "Sorry ... Sorry!" When no one moves she moans loudly. The assistant tells her: "No, Garance, you can say 'Sorry' as many times as you want, but you cannot pass here!" (Nov. 2015) 
In the first two sequences, the class difference between Owen and Neyla versus Chloe, Livia, and Andy takes the form of a contrast between interactional efforts that are not sustained by verbalization and strategic usages of a polite formula. This aspect cannot be analyzed here due to space constraints, but note that Chloe's politeness does not simply involve the word "please," but also includes a "conventionalized indirectness" (Brown and Levinson 1987:70), namely the "Can you ... ?" form (instead of a direct "come!"). Usage of this form was also socially unequal in my field, once again in favor of socially privileged children.

In the second sequence, Livia shifts to politeness after a first unsuccessful verbal attempt to make me leave (exactly as Garance shifted from “Oh!” to "Wilfried!"). Livia’s speech acts demonstrate that, from her viewpoint, saying "Sorry" improves her chances of achieving goals, at least when dealing with an adult. Importantly, the use of "madam," which was at odds with the situation (I am a man, and all the children were aware of that), confirms the "conventionalized" dimension of such speech. Polite forms of address are not "invented" on the spot: they are imported, so to speak, from interactional routinized settings where children have previously experienced their social power. Even though the current situation did not exactly match a previous one (in terms of gender identity), Livia and Andy were confident that some empowerment would likely result from their strategic application. This practical logic is crucial: it can put generic, institutionalized, and conventionalized symbols in the service of specific, personal goals.

Finally, the third sequence, echoing the second, gives an even clearer illustration of the power effect very young children anticipate when they resort to politeness. In both French and English, a polite word such as "Please" is sometimes called a "magic word," particularly among caregivers when trying to explain to young children that only a polite request will work. Indeed, these polite words are magical in the sociological, Maussian sense: "please" contains the 
collective power of the whole society, and its evocation in concrete, individual actions may produce social obligations (Mauss [1905] 2001). Garance expected magical effects from her repeated use of the word "sorry." She seemed to believe the magic would be strong enough to move no fewer than three persons, including an adult. She was wrong, as explicitly confirmed by the assistant. Yet, we can easily imagine this is just a temporary problem of symbolic adjustment: with time, Garance will understand that "sorry" only supports weak types of symbolic empowerment, compared to verbal activities such as argumentation, narratives, and so on.

\section{POWER OVER OTHERS' PERCEPTIONS: THE VALORIZATION OF PERSONAL PROPERTIES}

Escaping Commonality

The ability to affect others' actions represents the most concrete aspect of early social empowerment, as children are subsequently oriented toward a shift in observable practices and localizable (adult) interventions. But social empowerment is also a matter of more abstract processes involving others' perceptions in their relative autonomy vis-à-vis effective behavior. ${ }^{\mathrm{V}}$ What is then at stake is not the immediate activity of surrounding interactants, but rather their mindset and cognitive operations. More precisely, children can try to affect how adults classify, identify, and valorize persons and things within the local interactional context. This effort concerns the valorization of their own person and things - two kinds of personal properties, as I call them, that are strongly connected in the early years of life.

The valorization of personal properties is constrained in the context of a daycare center. First, the center does everything it can to promote similarity in treatment and commonality among children. Even if this rule is not always respected, professionals are supposed to avoid individual praise, among other things. The reason is not just ideological (formal equality must prevail in public institutions) but also practical: if an adult praises a specific child, others may ask for the same treatment, at the expense of professional routines. Second, the material setting of the 
daycare center limits the possession of personal objects. Most of the available objects, toys in particular, exist in series, so they are hardly the basis of singularization practices (i.e., they are not personal). Children are not allowed to monopolize objects, so durable appropriation of a special thing is not possible (i.e., they are not properties). The rare objects of personalization include personal clothes, comforters, and children's local productions such as drawings or sculptures. Assistants store children's comforters and art projects away from interactional contexts (inside children's individual lockers or in a separate room), precisely to avoid their differentiation effects. Only clothes (or hairdos) provide possible material supports for personalization; indeed, ethnographic observation confirmed this took place, sometimes with the (irrepressible) participation of an adult:

Ashanti [girl, 3:00, mother unemployed, from Cameroon] is sitting, wearing a Frozen outfit. The assistant notices it, and says it's nice. Ashanti smiles, and starts to caress her outfit with her hands. The children stare at her. (Jan. 2016)

Despite such exceptions, almost all the objects children can access in a daycare center are common in both senses of the term: virtually all children can get them, and they are not special things but ordinary, unremarkable ones.

As a consequence, children's experiences tend to be very common as well, as long as they are supported by the sole symbolic and material structures imposed by the daycare center (and its agents). Individual involvement and agentic behavior is thus crucial for valorizing personal properties. Language practices, in particular, especially as they become more elaborate, enhance children's power over others' perceptions. Children can use words to impart value —and sometimes even an extraordinary appearance - to their pretty common experiences. Showing and Naming Possessed Objects: Minimal Valorizations

As far as the valorization of possessed objects is concerned, the simplest strategies children used consisted of orienting adult perceptions toward the things they were currently 
holding. In such cases, valorization relies entirely on the higher status of the adult. The very fact that a social agent of proven importance (compared to the child) is paying attention to a toy, book, or drawing adds value to it. Children's strategies included non-verbal, signaling practices, such as pointing at an object, as well as putting an object directly in the adult's hands:

Maurice [boy, 2:02, mother caregiver, from Rwanda] gives me a firefighter helmet. I put it on my head for a while. He takes it back and instantly puts it on his own head, then he puts it back on mine, which makes him laugh. (Nov. 2015)

Giulia [girl, 2:04, mother researcher] picks up a leaf on the ground and brings it to me, but tries to take it back right away. She then goes to an assistant, gives her the leaf, and once again takes it back. During this short interaction, the assistant comments: "Wow, what a nice leaf! You're giving it to me? No? I'm giving it back to you?” (Dec. 2015)

As these sequences illustrate, putting an object into an adult's hand is all the more interesting for children considering that the triggered valorization process may exceed the simple physical association between an object and a valued person (the adult). When adults hold an object, they typically do something with it, and this may produce additional value. In the first sequence, I demonstrated a socially legitimate (funny) usage of the firefighter helmet, and thus contributed to its singularization (although half a dozen identical helmets were available in the room). In the second sequence, the assistant's positive and publicly stated qualification of the leaf ("Wow, what a nice leaf!") helped the child's effort to improve its value (although many leaves were available on the terrace in autumn). In both cases, the efficiency of the valorization process for the child was visible. Both Maurice and Giulia tried to take their object back as soon as the adult had valorized it in some way. This is clearly not a transfer practice (a possible but very rare phenomenon at this age). The goal is to have one's material properties perceived and used by a relatively dominant interactant in order to challenge its banality.

Basic verbal resources permit a first improvement of valorization strategies. Instead of simply pointing, children can add a "Look!" that is typically oriented toward an adult's 
perception - a basic social tool whose importance is underscored in cultural psychology (Bruner 1983). Children can also call adults by their names or use politeness, as they do when they want to affect adults' actions ( see the previous section). Words give children the possibility of more autonomous valorization strategies, namely strategies that do not rely on the goodwill of adults.

It starts with the utterance of the specific name of the owned object. Common nouns used to designate basic things do not seem so common, from the viewpoint of young children. Children find a special interest in using names and producing public references to them. When pointing, giving, or attracting attention through interjections such as "Look!", children often add the name of the object in question, using expressions such as "Look, a spoon!" or "It's the blue one" (for a pen). It would be mistaken to think that, in doing so, children are only trying to demonstrate their lexical knowledge, as another frequent formula children use is to have the object named by an adult, as in the following sequences:

Katsuko [girl, 2:05, mother marketing supervisor, from Japan] hands me a yellow pen, and says: "Oh! What is this?" (Nov. 2015)

Cléa [girl, 2:04, mother researcher] brings a wooden knife to the assistant and asks "What is this?" The assistant answers, smiling: "You know very well, you little monkey (coquine) ..." Soon after, Maxwell [boy, 2:02, mother college student, from Congo] asks the same thing regarding a cup. (Nov. 2015)

Jane [girl, 2:11, mother cook, from Togo] asks me the color and name of a few plastic figurines she is holding in her hand. I object that she knows the name perfectly well, and she confirms: "Fishes!" she says, smiling. (Dec. 2015)

As the last two sequences show, children who are able to ask questions like "what is this?" generally know the name of most familiar objects such as a pen, knife, or cup. Here, the point is not to learn a lexeme, but rather to obtain public confirmation from an adult (the most legitimate kind of social agent around) that the thing they are holding is sufficiently recognized as possessing a special name, and having its dedicated place within the lexicon. For adults, the social credit carried by the names of objects may admittedly seem very low, because adults 
usually have many other symbolic ways of valorizing their personal properties. But very young children are apparently sensitive to the elementary role of names in designating parts of the world that, in a given linguistic community, deserve to be distinguished. ${ }^{\mathrm{vi}}$

\section{The Power of Fictionalization}

The development of language skills, which occurs differently depending on social background (Gilkerson et al. 2017), allows for more elaborate valorization strategies. Some are in keeping with naming, in that they consist solely of highlighting the special qualities of personal objects (e.g., their big size) that could make them different or better in the eyes of others:

Aymeric [boy, 2:07, mother marketing manager] comes close to me, points at a truck he is playing with, and says: "Big truck, it is BIG! Firefighters' truck." He moves the truck back and forth on the ground in front of me. (Jan. 2016)

Yet the most impressive (and socially selective) valorization strategies are different. They contain remarkable detours from (normative) descriptions of personal properties, and take the more abstract form of a fictionalization.

Fictionalization starts when children give fictional names to objects. In the daycare center, those names often emerged during creative sessions. When very young children produce objects such as drawings, paintings, or sculptures, materially speaking the output consists of indistinctive doodles, mixed colors, and random shapes. But as the following sequences illustrate, as long as they can speak (French) and are socially ready to initiate verbal interactions, children can find ways to make others see their productions under a much better light:

Staring at a simple ball of dough she was handling until now, Cléa [girl, 2:04, mother researcher] suddenly states: "Ninoceros!" (for "Rhinoceros"). (Nov. 2015)

Jim [boy, 2:11, mother cook, from Togo] whirls his pen very rapidly; his drawing spills over the sheet. A second later, he asks the assistant: "Is it the sun?" (Nov. 2015) 
Lola [girl, 1:11, mother childcare assistant] has just drawn two parallel lines on her blank sheet, but she says: "A fish!" The assistant reacts: "A fish? Oh, what a nice one!" (Nov. 2015)

Children do not choose fictional names randomly. In fact, children do not "change" their simple ball of dough or approximate circle into common or despised animals (e.g., an ant or a rat) or into ordinary natural elements (e.g., a pond). Instead, they target relatively "prestigious" things (i.e., things their society recognizes as prestigious), such as a rhinoceros (a rare animal), the sun, or a fish (fish are a recurrent element in many French lullabies, including a real "hit" at the daycare center, Les petits poissons dans l'eau [The Little Fish in the Water]). Note that this implies some precocious social sense of what is important and what is not. ${ }^{\text {vii }}$ The last sequence confirms that such a symbolic practice may be an efficient vector of valorization, regardless of the objective appearance of the child's production. Despite her first dubious reaction (“A fish?”), the assistant ultimately praised Lola for her drawing. Without her comment, Lola would not have been congratulated. The valorization she obtained is clearly an output of her special enactment of symbolic power.

Similar practices are also seen during pretend play. In this case, children give fictional names to objects they did not produce but that are nonetheless personal, in the most basic sense that the children currently own them. Here are two examples:

Livia [girl, 2:10, mother schoolteacher] comes to the assistant, holding a purse filled with plastic cubes. She says: "Look! I bought candies!” (Nov. 2015)

Garance [girl, 2:09, mother purchasing manager] calls me: "Look, Wilfried!" She has put wooden pearls around each of her fingers. "So many jewels!" (Nov. 2015)

Once again, in these sequences, very common cubes and pearls are changed into relatively prestigious, exceptional items, such as candies and jewels. Children are pretending - in the normative sense of the term - that they have more (symbolically) than they actually do (materially). 
A problem with fictional names is that, at best, they lead to punctual and ephemeral shifts in others' perceptions. Once they have heard and sometimes acknowledged a valorizing word, adults or other children typically look at something else and go back to their own business. Sustaining a more durable shift in others' perceptions requires verbal skills that only children from the most (culturally) privileged social background can access. In this case, fiction is patiently extended from one word to another, creating a symbolic chain of continuous valorization. This implies verbal creativity and confidence, as illustrated by the following sequence:

Lou [girl, 2:05, mother advertiser] is sitting in the sandbox, constantly commenting on what she is doing. As she fills a plastic baby bottle with sand, she points out: "I am baking a cake ..." Soon she adds: "I am baking a cake ... for Mommy!" She repeats the sentence several times. Cléa [girl, 2:05, mother researcher], hearing Lou's words, eventually asks her: "Are you baking a cake?" The assistant, who is near the scene, follows up: "What sort of cake?" Lou answers: "A strawberry cake!" . . [A few minutes later] Lou, still handling the baby bottle filled with sand, says: "I baked a cake for Santa." (Dec. 2015)

In principle, early fictionalization could be a pure act of imagination, an occasion for children to use words to follow a wide variety of semantic directions. However, language practices such as Lou's are usually oriented toward the same symbolic end of social valorization. The bottle of sand is first changed into a cake, an object socially associated with good, if not extraordinary, events. Then the cake becomes a cake "for Mommy!"; in other words, not a regular cake but a special present "for" one of the child's most important social agents (her mother). A similar process occurs later, when Lou mentions "a cake for Santa," with Santa being another important social agent, albeit of a less embodied kind. Valorization goes one step further when Lou imagines a "strawberry cake," in other words a rich cake with special rather than ordinary fruit.

This sequence also shows that fictionalization, like other early language practices, may take a semi-cooperative form. Here the child's performance is realized with help from bystanders, 
who "scaffold" it (Bruner 1983) by introducing comments and questions sustaining the child's effort (e.g., the assistant when she asks "What sort of cake?") or by providing encouragement (e.g., as Cléa does, when she shows interest through the question: “Are you baking a cake?"). Young children's efforts to exert power over others through their first verbalizations does not necessarily exclude participation by others. Sometimes children can only count on themselves, on their individual symbolic dispositions and resources, in their efforts to affect others-typically when children want to make something happen that is explicitly refused by everyone around them. Other times, notably when the practical goals at stake are not really conflictual, the immediate environment may well participate in its own symbolic control.

\section{Distinction for Beginners?}

Through the language practices I reviewed, children do not just affect the perception of what they have, but they also affect the perception of what they are, as persons. First, having and being are not so different, especially for a young child. "It is clear," William James ([1890] 1950:291) noted, "that between what a man calls me and what he simply calls mine the line is difficult to draw." Modern developmental psychology has confirmed this general principle: "we do project and identify with things that become an intrinsic part of us and who we are for ourselves as well as the outside world" (Rochat 2014:35-36). This is exemplified in the case of drawings: their valorization in interactions naturally implies the valorization of their producer. But even when objects are not self-produced, the way they are seen and qualified by others is symbolically contagious and quickly concerns the children themselves. Having a different and special toy means being different and special—at least for a while.

Moreover, children are quick to use valorization techniques, such as showing, naming, or fictionalizing, for an object that abolishes the difference between "me" and "mine": their own 
body. In this case, children comment on their clothes, gestures, or technical skills in seeking approbation and praise from others:

Justine [girl, 2:06, mother consultant] arrives in the section, points at her shirt, and tells me with a proud voice: "There are flowers, there!” (May 2016)

Mila [girl, 3:00, mother business owner] calls the assistant: "Look, Aline, I'm doing the slide!" (Jun. 2016)

Young children's attempts to affect others' perceptions can arguably be analyzed as an emergent process of social distinction, as long as we keep in mind, in line with current cultural sociology, that distinction corresponds not just to structural phenomena but practical ones as well. The early valorization of personal properties, whether material possessions or individual characteristics of the body (in action), involves social processes that anticipate more complex symbolic management, like the one involved in classical cultural consumption. Bourdieu (1984) insisted that watching certain movies or listening to certain music may be less important in the dynamic of distinction than the way people do it, including the way they talk about movies or music. Similarly, as far as symbolic differentiation is concerned, the objective appropriation of given toys, spaces, or books in a daycare center may have less importance than children's unequal ability to present, show, and describe them to others.

In any event, thinking in terms of emergent social distinctions underscores that children's attempts to have power over others' perceptions are not just a question of here-and-now interactions. With repetition, the exercise of such power may lead to differential symbolic accumulation, acknowledged by the children themselves and the people around them. As previous work shows, the ability of the most verbally skilled children to be repeatedly praised, even by non-familial social agents such as the assistants, may contribute to the affirmation of a steady, distinctive, and socially useful "sense of entitlement" (Calarco 2011; Lareau 2003; Streib 2011). Moreover, these children may be identified by socialization agents as symbolically 
specific, and socially distinct, with possible effects on caregiving choices and practices. During interviews with assistants conducted after ethnographic observations, I asked them to describe each child in a few words. They often had difficulty proposing a specific description, given the relative similarity of the children, and their professional obligation to treat them equally. Nonetheless, a child such as Lou—a champion of fictionalization—was credited with fairly distinctive personal properties and described as "easygoing," "clever," "very mature," able to "speak very well," "friends with everyone," and "a little monkey." Although fairly elementary, this precocious distinction was consistent enough to sketch out a positive and stable definition of the little girl, and to secure a relatively good symbolic place for her, among her local peers.

\section{DISCUSSION AND CONCLUDING REMARKS}

"In theory at least," Goffman (1981:61) writes, "a speaker should be able to present a statement that solely reports pure fact. ... Very often, in contrast, a speaker presents a 'directive,' that is, words whose point (or illocutionary force) is to urge the hearer to do something, the urging varying in degree from gentle requests to harsh commands." My ethnographic study of early symbolic practices demonstrates that such "directive" use of words is not a late output of language socialization; it is not an optional practice that only occurs when young humans are able to "communicate." On the contrary, gaining power over others' actions and perceptions is a core challenge for early symbolic life. I analyzed several symbolic practices through which 2- and 3year-olds try, with varying degrees of success, to control the people around them, especially how adult caregivers act with them and see them. From the most basic to the most refined, these practices include signaling personal goals through simple gestures and cries; showing or giving personal possessions and having them valorized in some way; calling people by their name, not only to improve the precision of signaling, but also to add a normative dimension to calls (I know 
you, you have to help me); naming objects (literally), or having them named through a question, to exhibit their socially acknowledged existence (objects have their dedicated place within the lexicon); using polite forms of address, that is, a previously experienced and conventionalized way of (gently) forcing interlocutors; giving extraordinary (fictional) names to objects to escape their commonality; and connecting these names through (fictional) narratives to evoke virtual social situations that are far more interesting than the real ones.

Accessing the most refined practices and the subtlest means of symbolic empowerment is not a pure question of age. Being old enough for politeness or fictionalization is necessary but not sufficient. Social class seems especially relevant, because it matches the most important variations in symbolic resources, as measured by developmental, usage-based psycholinguistics, and as naturally captured by ethnography. ${ }^{\text {viii }}$ Differential exposure to language, first at home, results in differential possibilities in "finding the right words" in interaction, and probably in differential readiness for public speech acts (e.g., a child who knows a word or phrase may be unable to actually pronounce it, because the child feels it is not appropriate behavior). Ultimately, these social differences in symbolic resources translate into emergent social inequalities even at a very young age, particularly in a context where non-symbolic ways of interacting are strictly controlled (e.g., in a daycare center). Because of their verbal skills, children from the most privileged social backgrounds may get more opportunities to customize their care. Concretely, they will more easily obtain things that are not spontaneously given to them, "convince" adults to take their side in conflicts with peers, or provoke situations where they are congratulated (for what they have or what they do). To a certain extent, my observations suggest these opportunities may crystallize and hence correspond to stabilized and privileged identities, in other words to elementary forms of distinctions. 
Observing and analyzing early language practices from a sociological viewpoint offers new theoretical insights into symbolic power as performed in concrete interactions. Despite their diversity, the reviewed practices share a common social logic. Whether for calling, naming, asking, or fictionalizing, the words children use always consist of a strategic evocation within the local interactional context: children are trying to "recruit" an external social authority to improve their individual situation. This recruitment is partly interactional, and to this extent takes the concrete form of attracting persons endowed with authority (e.g., adults). In this respect, the practical challenge for children is to reduce uncertainty about how the authority will be applied. At age 2 or 3, the ability to select one specific person and to incur the person's goodwill (typically through use of names and the evocation of familiarity) is already a distinctive asset. As time goes by, differential skills in argumentation or seduction will surely be helpful. That said, the early exercise of symbolic power already includes more abstract "recruitment" techniques. Beyond the attraction of persons, even young children know how to make strategic references to anonymous, general, secular conventions or institutions (in the Durkheimian sense). The authority of society as a whole, and especially its linguistic community, is consequently at stake. When a child adds "sorry" or "please" to a request, the point is not just to soften it, but also to suggest that the pursuit of personal goals is realized in conformity with authorized manners. In other words, through the "magic" of politeness, the child's will suddenly must be satisfied in the name of society. Similarly, when a child changes an ordinary object into a jewel, or when a fairly vague sequence of gestures becomes "Baking a strawberry cake for Mommy," the expected valorization effect is clearly due to a practical reference to society (as long as this society generally enjoys jewels and baking cakes). The child's objects and actions become different, and distinctive, only because they happen to represent things and moments that are normatively recognized by the whole collectivity. 
Such an analysis implies a possible critique of the literature on early childhood, both in developmental psychology and the sociology of childhood. Although this work insists on children's subjectivity and autonomy, these subdisciplines now almost always include careful attention to early sociality. However, this sociality is often reduced to interpersonal, interactional relations, at the expense of more abstract social relations. Yet as my study shows, relations to sociohistorical institutions (not just here and now interactions) constantly shape and orient individual practices from the very start of human life, notably through language. Children's subjectivity and agency, in particular, cannot be interpreted without reference to these (adult) institutions. Even the earliest manifestations of personal goals and desires are institutionally structured. First, what young children want is more or less fixed by sociohistorical institutions: in my study, children would not have evoked "cakes" if their social value was not institutionalized. Second, from the very beginning of human life, the achievement of goals and the expression of desires depends on institutional means: polite forms of address, for instance, represent an interactional resource for children only because they are acknowledged, legitimate ways of expressing personal interests.

My results also question developmental psychology and the sociology of childhood in putting power and domination not at the periphery but at the very center of children's experiences. Indeed, in today's developmental psychology, early childhood behavior seems less and less connected to power-related issues. Psychoanalytic approaches to childhood have been marginalized (Schechter 2014), which may have led to marginalization of the idea that conflict and opposition play a role in developmental dynamics. For sociologists of childhood, attempts to highlight children's social agency is usually linked to what we may call a cuteness bias - children generally seem to act nicely and to be driven by good intentions, not by selfish interests and agonistic tendencies. For instance, in exploring cultural activity, scholars typically refer to 
children's will to "connect" and "belong," rather than distinction (Pugh 2011). But the symbolic efforts to capture adult attention toward a possessed toy are difficult to interpret as a consequence of belonging strategies. Rather, they constitute an elementary pathway toward some singularization, or distinctive power, within a child's group.

To some extent, my findings echo the work of ethnomethodologists. They too have tried to understand, on the basis of direct observation of children's interactions, and of the language techniques children use more or less consciously, how young humans gradually manage to impose their "line of action" to others (Filipi 2009; Gardner and Forester 2010; Keel 2016; Sacks 1992). For instance, Sacks's (1992:343) famous analysis of "You know what, Daddy?"-a question from the child forcing the adult to return a question to the child ("No, what?"), and thus granting the child a voice — shares common features with the analysis I proposed, notably regarding attention management techniques. However, there are important theoretical differences. In line with a persistent functionalist/integrationist conception of "socialization" (Guhin, Calarco, and Miller-Idriss 2021), ethnomethodology tends to reduce the exercise of symbolic power, especially by children, to an effort to become a "competent member" of society. Moreover, this search for "membership" is often equated with children's will to participate in (adult) conversations, whether it is simply a matter of securing a "conversational turn," or more subtly, making sure other social agents will give some value to what the child says (what this literature calls "epistemic authority" [see Heritage and Raymond 2005]). Yet it is clear the symbolic power discussed here goes further than that. The children I observed are not aiming for generic, and in fact quite abstract, recognition as full members of society. Rather, they are pushing their special interests, which in many cases are opposed to those of others, or at any rate do not serve the collective functioning. Those interests derive from specific social positions and dispositions, and sociological analysis cannot bracket them anymore (as ethnomethodology does). This is 
particularly true because the situation in the social space implies differences in the symbolic and linguistic resources a child can mobilize, and therefore unequal access to symbolic power. In concrete terms, Sacks seems to consider the strategic use of a preface such as "You know what?" universal among 3-year-olds, but this premise deserves a true discussion, on an empirical basis; at the theoretical level, this implies accepting the existence of a priori social structuration, which operates below, or before, the interaction.

More generally, my ethnographic and sociogenetic approach to symbolic power challenges theoretical proposals that tend to separate, even partially, the exercise of power from power structures. Reed (2013:207, emphasis added), for example, considers the "performative" dimension of power (what people do to prevail in interaction) is not reduced to the instantiation of the dimension he calls "discursive" (e.g., ideologies, legitimate cultural forms), for it corresponds above all to "the situated effectiveness of acts themselves as movers of the world." But this statement is a bit mysterious. It seems to endorse the idea of a sui generis power, which would arise in and from interaction. Yet, one might exercise power precisely when individual action is enhanced by its connection with social entities that exist beyond the local, interactional situation. Then, as far as symbolic power is concerned, the valorization of persons and things does not rely any more on the sole immediate demonstration, here and now, of their advantages for the ongoing action. It passes by their association with qualifications and symbolic forms, which history and institutions have charged in advance with a relatively shared legitimacy.

In short, small (individual, local, interactional) powers stem by definition from big (collective, generic, institutional) powers. This is the fundamental sociological truth of power, which young children practically, progressively, and unequally discover. Children experience the poverty, that is, the social weakness, of their action, as long as it refers only to their own 
perceptions and desires. This pushes them to look for the strategic support of the communitywhich, at the most elementary scale, is nestled in everyday language.

\section{REFERENCES}

Alink, Lenneke R., Judi Mesman, Janties Van Zeijl, Mirjam N. Stolk, Femmie Juffer, Hans M. Koot, Marian J. Bakermans-Kranenburg, and Marinus H. Van Ijzendoorn. 2006. "The Early Childhood Aggression Curve: Development of Physical Aggression in 10- to 50-Month-Old Children." Child Development 77(4):954-966.

Bernstein, Basil. 1971. Class, Codes and Control, Vol. 1:Theoretical Studies Towards a Sociology of Language. London: Routledge.

Bourdieu, Pierre. 1984. Distinction: A Social Critique of the Judgement of Taste. New York: Routledge.

Bourdieu, Pierre. 1993. Language and Symbolic Power. Cambridge, MA: Harvard University Press.

Bourdieu, Pierre. 1994. "Structures, Habitus, Power: Basis for a Theory of Symbolic Power." Pp. 155-199 in Culture/Power/History: A Reader in Contemporary Social Theory, edited by N. B. Dirk, G. Eley and S. B. Ortner. Princeton, NJ: Princeton University Press.

Bourdieu, Pierre. 2000. Pascalian Meditations. Stanford, CA: Stanford University Press.

Bourdieu, Pierre. 2014. On the State: Lectures at the Collège de France (1989-1992). Cambridge, UK: Polity Press.

Bourdieu, Pierre, and Jean-Claude Passeron. 1977. Reproduction in Education, Society, and Culture. Beverly Hills, CA: Sage.

Brown, Stephen C., and Penelope Levinson. 1987. Politeness: Some Universals in Language Usage. Cambridge, UK: Cambridge University Press.

Bruner, Jerome S. 1983. Child's Talk: Learning to Use Language. New York: Norton.

Calarco, Jessica M. 2011. “'I Need Help!' Social Class and Children’s Help-Seeking in Elementary School.” American Sociological Review 76(6):862-882.

Calarco, Jessica M. 2014. "Coached for the Classroom: Parents' Cultural Transmission and Children's Reproduction of Inequalities.” American Sociological Review 79(5):1015-1037.

Cerulo, Karen A. 2002. Culture in Mind: Toward a Sociology of Culture and Cognition. New York: Routledge.

Cerulo, Karen A. 2018. "Scents and Sensibility: Olfaction, Sense Making, and Meaning Attribution." American Sociological Review 83(2):361-389.

Corsaro, William A. 1985. Friendship and Peer Culture in the Early Years. Norwood, NJ: Ablex. Corsaro, William A. 1997. The Sociology of Childhood. Thousand Oaks, CA: Pine Forge Press.

Dahl, Robert. 1957. "The Concept of Power.” Behavioral Science 2(3):201-215. 
d'Apice, Katrina, Rachel M. Latham, and Sophie von Stumm. 2019. "Naturalistic home observational approach to children's language, cognition, and behavior." Developmental Psychology, 55(7):1414-1427.

DiMaggio, Paul. 1997. “Culture and Cognition.” Annual Review of Sociology 23:263-287.

Eriksson, Marten, Peter B. Marschik, Tiia Tulviste, Margareta Almgren, Miguel Pérez Pereira, Sonja Wehberg, Ljubica Marjanovic, Frederique Gayraud, Melita Kovacevic, and Carlos Gallego. 2012. "Differences Between Girls and Boys in Emerging Language Skills: Evidence from 10 Language Communities." British Journal of Developmental Psychology 30:326-344.

Emirbayer, Mustafa, and Ann Mische. 1998. "What is Agency?" American Journal of Sociology 103(4):962-1023.

Farroni, Teresa, Stefano Massacesi, Donatella Pividori, and Mark H. Johnson. 2004. "Gaze Following in Newborns." Infancy 5(1):39-60.

Filipi, Anna. 2009. Toddler and Parent Interaction: The Organisation of Gaze, Pointing, and Vocalisation. Amsterdam: John Benjamins.

Fine, Gary A., and Kent L. Sandstrom. 1988. Knowing Children: Participant Observation with Minor. Newbury Park, CA: Sage.

Friemel, Thomas N. 2011. "Network Dynamics of Television Use in School Classes." Social Networks 34(3):346-358.

Gardner, Hilary, and Michael Forrester, eds. 2010. Analysing Interaction in Childhood: Insights from Conversation Analysis. Chichester, UK: Wiley-Blackwell.

Gilkerson, Jil, Jeffrey A. Richards, Steven F. Warren, Judith K. Montgomery, Charles R. Greenwood, D. Kimbrough Oller, John H. L. Hansen, and Terrance Paul. 2017. "Mapping the Early Language Environment Using All-Day Recordings and Automated Analysis." American Journal of Speech-Language Pathology 26(2):248-265.

Goffman, Erwin. 1961. Asylums: Essays on the Situation of Mental Patients and Other Inmate. New York: Anchor Books.

Goffman, Erwin. 1981. Forms of Talk. Philadelphia: University of Pennsylvania Press.

Gries, Stefan T., and Dagmar Divjak. 2012. Frequency Effects in Language Learning and Processing. Berlin: Mouton de Gruyter.

Guhin, Jeffrey, Jessica M. Calarco, and Cynthia Miller-Idriss. 2021. "Whatever Happened to Socialization?" Annual Review of Sociology 47:109-129.

Johnson, Scott P., Juliet Davidow, Cynthia Hall-Haro, and Michael C. Frank. 2008.

"Development of Perceptual Completion Originates in Information Acquisition." Developmental Psychology 44(5):1214-1224.

Hay, Dale F., Alison Nash, Marle Caplan, Jan Swartzentrubern, Fumiko Ishikawa, and Jo Ellen Vespo. 2011. "The Emergence of Gender Differences in Physical Aggression in the Context of Conflict between Young Peers." British Journal of Developmental Psychology 29(2):158-175.

Heritage, John and Geoffrey Raymond. 2005. "The Terms of Agreement: Indexing Epistemic Authority and Subordination in Talk-in-Interaction." Social Psychology Quarterly 68(1):15-38. 
Højholt, Charlotte and Dorte Kousholt. 2014. "Participant Observations of Children's Communities. Exploring Subjective Aspects of Social Practice." Qualitative Research in Psychology 11(3):316-334.

James, Alison and Allan Prout. 1990. Constructing and Reconstructing Childhood: New Directions in the Sociological Study of Childhood. Oxford,UK: Routledge.

James, William. [1890] 1950. The Principles of Psychology. New York: Dover.

Keel, Sara. 2016. Socialization: Parent-Child Interaction in Everyday Life. London: Routledge.

Ladegaard, Hans J. 2004. "Politeness in Young Children's Speech: Context, Peer Group Influence and Pragmatic Competence.” Journal of Pragmatics 36(11):2003-2022.

Lareau, Annette. 2003. Unequal Childhoods: Class, Race, and Family Life. Berkeley: University of California Press.

Lancy, David F. 2012. “Unmasking Children's Agency.” AnthropoChildren 1(2). https://digitalcommons.usu.edu/sswa_facpubs/277.

Lieven, Elena. 2010. "Input and First Language Acquisition: Evaluating the Role of Frequency." Lingua 120(11):2546-2556.

Lignier, Wilfried. 2019. Prendre. Naissance d'une pratique sociale élémentaire. Paris: Seuil.

Lignier, Wilfried. 2021. "The Discovery of Symbolic Violence: How Toddlers Learn to Prevail with Words." Ethnography 22(2):246-266.

Lignier, Wilfried and Julie Pagis. 2017. L'Enfance de l'ordre. Comment les enfants perçoivent l'ordre social. Paris: Seuil.

Lizardo, Omar. 2006. "How Cultural Tastes Shape Personal Networks.” American Sociological Review 71(5):778-807.

Lizardo, Omar. 2016a. "Why 'Cultural Matters' Matter: Culture Talk as the Mobilization of Cultural Capital in Interaction.” Poetics 58:1-17.

Lizardo, Omar. 2016b. "Cultural Symbols and Cultural Power." Qualitative Sociology 39(2):199204.

Lukes, Steven. 2005. Power: A Radical View, 2nd ed. New York: Palgrave-MacMillan.

Mauss, Marcel. [1905] 2001. A General Theory of Magic. New York: Routledge.

Miller, Peggy J., Grace E. Cho, and Jeana R. Bracey. 2005. "Working-Class Children's Experience through the Prism of Personal Storytelling." Human Development 48(3):115-135.

Mills, Sara. 2015. "Language, Culture and politeness.” Pp. 129-140 in The Routledge Handbook of Language and Culture, edited by F. Sharifian. Abingdon, UK: Routledge.

Pugh, Allison J. 2009. Longing and Belonging: Parents, Children and Consumer Culture.

Berkeley: University of California Press.

Pugh, Allison J. 2011. "Distinction, Boundaries or Bridges?: Children, Inequality and the Uses of Consumer Culture.” Poetics 39(1):1-18.

Pugh, Allison J. 2014. "The Theoretical Costs of Ignoring Childhood: Rethinking Independence, Insecurity and Inequality." Theory and Society 43(1)71-89. 
Qvortrup, Jens, William A. Corsaro, and Michael-Sebastian Honig. 2009. The Palgrave Handbook of Childhood Studies. Basingstoke, UK: Palgrave.

Reed, Isaac A. 2013. "Power: Relational, Discursive, and Performative Dimensions." Sociological Theory 31(3):193-218.

Rochat, Philippe. 2014. Origins of Possession. Owning and Sharing in Development. Cambridge, UK: Cambridge University Press.

Saxton, Colin. 2017. Child Language: Acquisition and Development, $2^{\text {nd }}$ Edition. Thousand Oaks, CA: Sage.

Schechter, Kate. 2014. Illusions of a Future: Psychoanalysis and the Biopolitics of Desire. Durham, NC: Duke University Press.

Streib, Jessie. 2011. "Class Reproduction by Four Year Olds.” Qualitative Sociology 34(2):337352.

Swartz, David L. 2013. Symbolic Power, Politics, and Intellectual: The Political Sociology of Pierre Bourdieu. Chicago: Chicago University Press.

Swidler, Ann. 1986. "Culture in Action: Symbols and Strategies." American Sociological Review 51(2):273-286.

Tomasello, Michael. 2003. Constructing A Language: A Usage-Based Theory of Language Acquisition. Cambridge, MA: Harvard University Press.

Tomasello, Michael. 2009. "The Usage-Based Theory of Language Acquisition.” Pp. 69-87 in The Cambridge Handbook of Child Language, edited by E. L. Bavin. Cambridge, UK:

Cambridge University Press.

Tribushinina, Elena, and Steven Gillis. 2017. "Advances and Lacunas in Usage-Based Studies of First Language Acquisition." Pp. 13-47 in Usage-Based Approaches to Language Acquisition and Language Teaching, edited by J. Evers-Vermeul and E. Tribushinina. Boston: De Gruyter.

Vaisey, Stephen. 2009. "Motivation and Justification: A Dual-Process Model of Culture in Action.” American Journal of Sociology 114(6):1675-1715.

Vaisey, Stephen, and Omar Lizardo. 2010. “Can Cultural Worldviews Influence Network Composition?" Social Forces 88(4):1595-1618.

Vaisey, Stephen, and Lauren Valentino. 2018. "Culture and Choice: Toward Integrating Cultural Sociology with the Judgment and Decision-Making Sciences." Poetics 68:131-143.

Vincini, Stefano, Yuna Jhang, Eugene H. Buder, and Shaun Gallagher. 2017. "Neonatal Imitation: Theory, Experimental Design, and Significance for the Field of Social Cognition." Frontiers in Psychology. https://www.frontiersin.org/articles/10.3389/fpsyg.

Vygotsky, Lev. [1934] 1986. Thought and Language. Cambridge, MA: MIT Press.

Wacquant, Loïc J.D., and Aksu Akçaoğlu. 2017. "Practice and Symbolic Power in Bourdieu: The View from Berkeley" Journal of Classical Sociology 17(1):37-51.

Weber, Max. [1922] 2019. Economy and Society. Cambridge, MA: Harvard University Press. 


\section{Notes}

${ }^{\text {i }}$ Some studies in early language development (before age 3) suggest girls may be slightly more skilled than boys with respect to language (see, e.g., Eriksson et al. 2012). The empirical basis of these findings can be criticized due to the frequent use of indirect methods, such as parental reports.

ii In France, school is compulsory at age 3.

iii Children's power over other children's action is explored in Lignier 2019 and Lignier 2021.

iv All field notes are translated from the French. For reported speech, I tried to preserve the informal style of interactions and to include children's syntactical errors. When the English translation introduces a relatively important reformulation, I provide the French original in parentheses.

${ }^{\mathrm{v}}$ Of course, action always involves perception. A special consideration for perceptions themselves can nonetheless be analytically fruitful as long as they are not always embedded in actions, but can exist independently in the form of stabilized identifications of persons and things.

vi An anonymous reader rightly suggested that "What is this?" is also a game that adults like to play with toddlers. Undoubtedly, young children's emergent distinction strategies frequently benefit from the recycling of adult words, heard during the course of their daily socialization. Nonetheless, these words are not oriented to children's practical interests per se, therefore requiring a special effort by the child, on the spot. On the notion of symbolic recycling, forged in relation to older children, see Lignier and Pagis (2017).

vii We can hypothesize that the acquisition of such a social sense is linked to the unequal representation of objects within the culture children are exposed to. For example, with regard to animals, some famous ones (e.g., rhinos, elephants, lions) are the subject of many songs, books, and stories, whereas others are essentially overlooked, quite surprisingly in some cases given their common presence (e.g., pigeons).

viii This finding does not mean that gender and ethnicity are not important. Further research is needed on this point. 